\title{
Initial symptom presentation after high school football-related concussion varies by time point in a season: an initial investigation
}

Benjamin L. Brett ${ }^{1,2,3}$, Andrew W. Kuhn ${ }^{3}$, Aaron M. Yengo-Kahnn ${ }^{3,4}$, Zachary Y. Kerr ${ }^{5}$, Christopher M. Bonfield ${ }^{3,4}$, Gary S. Solomon ${ }^{3,4}$ and Scott L. Zuckerman ${ }^{3,4^{*}}$

\begin{abstract}
Background: Schedule-based and in-season factors (e.g., competition type) have been shown to be associated with symptom reporting patterns and injury severity in sport-related concussion (SRC). To determine if acute neurocognitive and symptom presentation following SRC differ by time point within a high school football season.

Methods: Multicenter ambispective cohort of high school football players who sustained a SRC ( $N=2594)$. Timing (early, mid, and late season) of SRC was based on median dates for the start of the pre-season, regular season, and playoffs of each states' football schedules. Analysis of covariance (ANCOVA) investigated differences across season period groups for: (1) neurocognitive test scores, (2) total symptom scores (TSS), and (3) individual symptom increases from baseline within 1-week post-injury.

Results: Significant group differences were observed in TSS, $F(2,2589)=15.40, p<0.001, \eta_{p}^{2}=0.01$, and individual symptom increases from baseline, $F(2,2591)=16.40, p<0.001, \eta_{p}^{2}=0.01$. Significant increases were seen from baseline to both midseason and late season in both TSS, $X^{2}=24.40, p<0.001, \Phi=0.10$ and individual symptoms, $x^{2}=10.32, p=0.006, \Phi=0.10$. Post hoc tests indicated a linear trend, with late-season injured athletes reporting approximately twice the TSS (13.10 vs. 6.77) and new symptoms (5.70 vs. 2.68) as those with early-season injuries.

Conclusion: In a cohort of American high school football student-athletes, those suffering SRC in the late-season time period had increased acute symptom burden. SRC sustained later in-season may require more conservative management.
\end{abstract}

Keywords: Sport-related concussion, Symptoms, Modifying factors, Neurocognitive function, ImPACT testing, Sport injury

\section{Key points}

- A "seasonality effect" was observed where American high school football players who sustained a SRC later in the season reported significantly increased total symptom scores and number of individual symptoms compared to earlier season SRCs.

\footnotetext{
* Correspondence: scott.zuckerman@vanderbilt.edu

${ }^{3}$ Vanderbilt Sports Concussion Center, Vanderbilt University School of Medicine, Nashville, TN, USA

${ }^{4}$ Department of Neurological Surgery, Vanderbilt University Medical Center, Nashville, TN, USA

Full list of author information is available at the end of the article
}

- Sports medicine professionals should be aware of external and situational factors affecting symptom reporting following SRC.

- The symptomology and presentation of SRC may vary significantly over the course of the football season.

\section{Background}

Sport-related concussion (SRC) accounts for $25-50 \%$ of all concussions sustained by children $[1,2]$ and occurs in roughly 1.1 to 1.9 million US athletes $\leq 18$ years [3]. SRC has become an international health concern, with 
public attention paid primarily to professional and elite athletes $[2,4]$. However, given the large number of youth athletes participating in contact sports every year $[5,6]$, the overall burden of this public health problem rests at the youth and high school level [7]. American football, in particular, accounts for $41 \%$ of all high school SRCs [7]. Two recent studies from the 2008/2009-2012/2013 and 2011/2012-2013/2014 seasons estimate the current rate of SRC among high school football players to be 8.2-9.21/10,000 athletic exposures [8, 9].

Concomitant with an increase in SRC diagnoses is heightened public awareness, healthcare utilization, and research [10-12]. A recent report by the Institute of Medicine called for more research surrounding SRC risk in athletes aged 5 to 21 years [13]. Several efforts have been directed towards the role of biopsychosocial factors influencing SRC incidence, presentation, and recovery. Several modifying factors have been found to influence both SRC incidence [14-17] and prolong recovery [18$24]$. In the acute post-concussion period, factors such as sex [25], history of concussion [26, 27], ADHD [28], and age $[15,29]$ have been shown to increase neurocognitive deficits, while sex or pre-existing psychiatric disorders have been associated with higher acute total symptom scores [30-32].

The identification of other sport-related modifying factors, beyond biopsychosocial variables, may also prove worthwhile. For instance, schedule-based and in-season factors, such as competition type [33-35] and injury mechanism [36], have been shown to be associated with symptom reporting patterns acutely and during recovery.

One trend that has yet to be investigated is the effect of seasonality, defined operationally as time point in the season, on acute presentation (symptom reporting and neurocognitive functioning) after SRC. The primary objective of this study was to investigate the effect of seasonality (early, mid, and late season) on acute neurocognitive performance and symptom burden following SRC in American high school football players. Due to the exploratory nature of this study, we adopted the null hypothesis, proposing that there would be no differences in initial presentation following SRC across season period groups.

\section{Methods}

\section{Study design and overview}

A retrospective analysis of prospectively collected data (ambispective design) was conducted. Participants included 2674 student-athletes from various high schools across the USA who underwent routine pre-season and post-concussion neurocognitive testing using Immediate Post-Concussion Assessment and Cognitive Testing (ImPACT) [37]. Anonymous, deidentified data were obtained for the study from the lead programmer at ImPACT, who was blinded to the purpose of the study. Due to the deidentified nature of the data abstraction, repeat injuries in the same athlete could not be controlled. Institutional Review Board (IRB) approval was obtained prior to analysis (IRB\# 120991), and the study was performed in accordance with the standards of ethics outlined in the Declaration of Helsinki.

\section{Selection of participants}

Following written, informed consent by the studentathlete and/or his parent/guardian, all participants completed a baseline neurocognitive test as part of routine athletic care. Baseline ImPACT testing was conducted in group settings during the pre-season and under the supervision of a sports medicine professional trained in the administration of ImPACT [38]; however, group sizes or administration procedures may have slightly varied across sites. High school football players who sustained a SRC from 2011 to 2016 were included in the analysis. Football was chosen due to its highest concussion rate among high school athletics [39]. Additionally, football was the only sport investigated to standardize season time points and to minimize potential confounds, such as different season durations and game schedules.

SRC diagnoses were made in accordance with the definition provided by the 2008 and 2012 International Concussion in Sport Group (CISG) guidelines [40, 41]. Diagnoses were made by certified athletic trainers (ATCs) or team physicians based on the following onfield/sideline signs or symptoms: (1) lethargy, fogginess, headache, dizziness, nausea, visual problems, photophobia, or phonophobia; (2) alteration in mental status; (3) loss of consciousness; or (4) amnesia. Grading systems of concussion severity were not utilized, based on the aforementioned CISG guidelines [40, 41]. All athletes included in the study completed a post-injury ImPACT test within 7 days of injury $(\mathrm{M}=4.21, \mathrm{SD}=1.68)$. Assessments that obtained a positive invalidity indicator, as designated by ImPACT [37], were not considered as eligible for the study and were excluded. Due to the inclusion of only valid tests as part of the data extraction, the precise number of invalid cases could not be specified. Of the total 2674 individual athletes who met these criteria, those with missing data $(n=48,1.8 \%)$ and reporting English as a second language $(n=32,1.2 \%)$ were excluded, resulting in a final sample of 2594 studentathletes.

\section{Data collection}

All data were obtained from ImPACT, including basic demographic and biopsychosocial information, four indices of neurocognitive functioning, and a self-reported symptom inventory [37]. The four individual 
neurocognitive indices yield composite scores for verbal memory, visual memory, visual motor speed, and reaction time. The self-report symptom inventory computes a total symptom scale (TSS), comprised of 22 common symptoms, each rated on a 0-6 Likert scale, with $0=$ none and $6=$ severe.

\section{Seasonality}

Season period ranges (early, mid, and late season) were defined based on published data/reports from all 50 states (+District of Columbia) for dates of high school football pre-season, regular season, playoffs, and final game. Following the precedent set by previous studies investigating injury rate differences across season periods, cut-points for group formation included preseason (early), regular season (mid), and postseason (late) $[42,43]$. Median dates for the start of pre-season, regular season, and playoffs across all available states were used to determine cut points for ranges. Pre-season was defined as training camp, exhibition games, or scrimmages. The median pre-season start date was $\mathrm{Au}$ gust 7 (range = July 30 to August 18; data available from 33 states), which was designated as the commencement of the early-season period. Regular season was defined as the scheduled games for all teams. The median regular season start date was August 27 (range $=$ August 18 to September 10; data available in 50 states), which was designated as the mid-season cutoff date. Late season was defined as the playoff games, where teams played single elimination games, based on record and seeding. The median playoff start date was November 5 (October 14-November 29; data was available for 50 states), which was designated as the cutoff of the late-season period. Median data for end of season date was November 26. Athletes were classified into season period groups (early, mid, and late) based on their date of SRC injury, which was extracted from post-injury ImPACT tests. Though these times mirrored pre-season, regular season, and playoffs, some overlap of periods likely existed between regions. Thus, early, mid, and late season were chosen to better represent the amalgamation of schedules.

\section{Neurocognitive and symptom outcomes}

Three a priori outcomes were determined: (1) neurocognitive test scores, (2) total symptom scores (TSS), and (3) increase in individual symptoms. A meaningful change for each outcome measure was defined as follows. For the outcomes of neurocognitive scores and TSS, a reliable change was based on meaningful change at the $80 \%$ confidence interval level [44]. To determine increase in number and severity of symptoms, a previously validated cutoff score (2+ symptoms, increased $1+$ point) was used to classify athletes as meaningfully changed from baseline [45].
The term "symptom burden" was collectively used when referring to both symptom outcomes (TSS and individual symptom increase).

\section{Statistical analysis}

Demographic and biopsychosocial data from each athlete's ImPACT evaluation were extracted and compared across seasonality groups using analysis of variance (ANOVA) tests. Variables that significantly differed between the early-, mid-, and late-season SRC groups were selected as covariates for subsequent analysis of covariance (ANCOVA) tests comparing outcome variables (i.e., post-injury scores and symptoms; Table 1). Baseline neurocognitive composite and symptom scores were also entered as covariates for their respective post-injury ANCOVA in order to control for individual differences at baseline. Separate ANCOVA tests were conducted for each post-injury ImPACT composite score and TSS. Due to the recent emphasis on individualized symptoms over TSS [46], differences in the number of symptoms that increased from baseline assessments to post-injury were compared across seasonality groups. Additionally, ANOVA tests were performed to compare individual symptom reporting for each of the 22 symptoms within the PCSS across the three groups, with a Bonferronicorrected significance (alpha) level set at 0.002 [47]. Separate chi-squared tests were performed to compare rates of reliable change from baseline for neurocognitive and symptom scores. Reliable change was based on meaningful change at the $80 \%$ confidence interval level [44]. Additionally, a chi-squared test was performed as a means to test individual symptom increases from baseline based on a previously validated cutoff score $(2+$ symptoms, increased 1+ point) [45]. Bonferronicorrected alpha level for multiple comparisons was set at 0.008 [47].

\section{Results}

A total of 2594 athletes were included in the final analysis for the early- $(n=418)$, mid- $(n=2078)$, and lateseason groups $(n=98)$. Demographic, medical, and neuropsychiatric history, and baseline neurocognitive and symptom scores are summarized (Table 1), along with accompanying between-group comparisons. Timing from SRC to post-injury assessment, measured in days, did not differ significantly between groups: early $(M=$ 4.09, $\mathrm{SD}=1.69)$, mid $(\mathrm{M}=4.24, \mathrm{SD}=1.68)$, and late $(\mathrm{M}$ $=4.18, \mathrm{SD}=1.68), F(2,2591)=1.52, p=0.22$. Across all three groups, $458(17.8 \%)$ athletes were evaluated within the first day post injury, 1258 (49.0\%) were evaluated at approximate 3 days following injury, and 850 (33.1\%) were evaluated between 4 and 7 days. Age emerged as the only factor that significantly differed across groups, $F(2,2591)=6.97, \quad p=0.001$, and was entered into 
Table 1 Baseline characteristics and comparisons of 2594 high school football athletes who sustained concussion in the early, mid, and late season

\begin{tabular}{|c|c|c|c|c|c|c|}
\hline Mean (SD) or $n(\%)$ & Early season $(n=418)$ & Midseason $(n=2078)$ & Late season $(n=98)$ & Total $(n=2594)$ & $F / X^{2}$ & $p$ value $^{*}$ \\
\hline \multicolumn{7}{|l|}{ Demographic factors } \\
\hline Age & $15.25(1.19)$ & $15.31(1.23)$ & $15.76(1.23)$ & $15.3(1.23)$ & 6.97 & 0.001 \\
\hline History of concussion & $116(27.8)$ & $596(28.7)$ & $34(35.4)$ & $746(28.8)$ & 2.29 & 0.32 \\
\hline Years playing at HS level & $1.65(1.90)$ & $1.73(1.96)$ & $2.13(2.40)$ & $1.73(1.97)$ & 3.88 & 0.21 \\
\hline Gender (male) & $418(100)$ & $2074(99.90)$ & $98(100)$ & 2590 & 1.00 & 0.61 \\
\hline Handedness (right) & $350(83.37)$ & $1792(86.23)$ & $84(85.71)$ & $2226(85.81)$ & 2.81 & 0.59 \\
\hline Country (USA) & $418(100)$ & $2068(99.50)$ & $98(100.00)$ & $2584(99.61)$ & 2.49 & 0.65 \\
\hline ADHD & $58(13.86)$ & $282(13.57)$ & $12(12.24)$ & $352(13.57)$ & 0.20 & 0.91 \\
\hline Learning disorder & $36(8.6)$ & $196(9.43)$ & $10(10.20)$ & $242(9.32)$ & 0.33 & 0.85 \\
\hline Days since injury & $4.09(1.69)$ & $4.24(1.68)$ & $4.18(1.73)$ & $4.21(1.68)$ & 1.52 & 0.22 \\
\hline \multicolumn{7}{|l|}{ Treatment history } \\
\hline Headaches & $44(10.50)$ & $260(12.90)$ & $12(12.80)$ & $316(12.18)$ & 1.08 & 0.58 \\
\hline Migraines & $36(9.10)$ & $146(7.30)$ & $6(6.40)$ & $188(7.24)$ & 1.72 & 0.42 \\
\hline Epilepsy/seizures & $0(0.00)$ & $18(0.90)$ & $0(0.00)$ & $18(0.69)$ & 4.50 & 0.11 \\
\hline Brain surgery & $0(0.00)$ & $4(0.20)$ & $0(0.00)$ & $4(0.15)$ & 0.99 & 0.61 \\
\hline Meningitis & $2(0.50)$ & $14(0.70)$ & $2(2.10)$ & $18(0.69)$ & 2.81 & 0.25 \\
\hline Alcohol/substance abuse & $0(0.00)$ & $2(0.10)$ & $0(0.0)$ & $2(0.07)$ & 0.49 & 0.78 \\
\hline Depression/anxiety & $8(2.00)$ & $46(2.30)$ & $2(2.10)$ & $56(2.15)$ & 0.15 & 0.93 \\
\hline \multicolumn{7}{|c|}{ Baseline neurocognitive and symptom scores } \\
\hline Verbal memory & $81.73(10.31)$ & $82.78(10.16)$ & $83.08(10.49)$ & $82.62(10.20)$ & 6.69 & 0.001 \\
\hline Visual memory & $72.46(12.95)$ & $74.14(12.83)$ & $70.24(13.90)$ & $73.74(12.83)$ & 0.82 & 0.44 \\
\hline Visual motor speed & $34.72(6.26)$ & 35.19 (6.95) & $35.00(6.14)$ & $35.11(6.79)$ & 1.05 & 0.35 \\
\hline Reaction time & $0.63(0.09)$ & $0.63(0.09)$ & $0.62(0.08)$ & $0.63(0.09)$ & 11.02 & $<0.001$ \\
\hline Total symptom score & $6.02(10.60)$ & $4.35(7.95)$ & $4.54(8.37)$ & $4.54(8.37)$ & 1.88 & 0.15 \\
\hline
\end{tabular}

Italics indicates selection of covariates to control for in outcome measure statistical modeling ${ }^{*} p$ values of one-way ANOVAs (continuous variables) and chi-square analyses ( $x^{2}$; binary and categorical variables) for comparison of those who sustained concussion in the early, mid, or late season

ANCOVA tests as a result. Verbal memory, $F(2,2591)=$ $6.69, p=0.001$, and reaction time, $F(2,2591)=11.02, p$ $<0.001$, significantly differed across groups as well. Regardless of statistical significance, each baseline test was entered as a covariate for their respective post-injury neurocognitive or symptom score as part of each ANCOVA.

\section{Neurocognitive performance}

No significant differences between the three groups were observed for any of the four neurocognitive composite scores (Tables 2 and 3). Classification rates of neurocognitive scores as injured from baseline at the $80 \%$ confidence interval did not significantly differ between the three groups (Table 4).

\section{Total symptom score}

Results revealed significant differences in TSS across all three groups, $F(2,2589)=15.40, p<0.001$, and partial $\eta_{\mathrm{p}}^{2}=0.01 \quad$ (Tables 2 and 3; Fig. 1). Tukey's honest significant difference (HSD) post hoc tests indicated that these differences existed at all three levels and were linear, with mid-season athletes reporting significantly higher TSS than early-season athletes (mean difference $=2.54, p=0.001$ ) and late-season athletes reporting significantly higher TSS than mid-season athletes (mean difference $3.75, p=0.01$ ). Late-season athletes reported significantly higher TSS than early-season athletes (mean difference $=6.30, p<0.001$ ). On average, TSS from athletes who were injured in the late-season group were twice that of athletes who were injured early in the season (13.10 vs. 6.77). Significant differences in being classified as reliably changed in TSS from baseline at the $80 \%$ confidence interval were observed between the early (15.31\%), mid (23.20\%), and late season (36.73\%) injured athletes, $\chi^{2}=24.40, p<0.001$, and $\Phi=0.10$.

\section{Individual symptoms}

A similar trend was observed for the number and severity of increased individual symptoms from baseline, 
Table 2 Comparison of post-injury outcome measures among athletes who sustained an early, mid, and late season concussion

\begin{tabular}{|c|c|c|c|c|c|c|}
\hline Post-concussion outcome: mean (SD) & Early season $(n=418)$ & Midseason $(n=2078)$ & Late season $(n=98)$ & $F$ & $p$ value & $\eta_{\mathrm{p}}^{2 c}$ \\
\hline Verbal memory $^{a}$ & $83.13(12.99)$ & $83.35(13.22)$ & $81.76(14.98)$ & 1.55 & 0.21 & - \\
\hline Visual memory ${ }^{a}$ & $73.27(12.96)$ & $74.60(14.63)$ & $69.65(15.18)$ & 2.68 & 0.07 & - \\
\hline Visual motor speed ${ }^{\mathrm{a}}$ & $35.86(6.99)$ & $36.21(7.60)$ & $35.51(6.80)$ & 0.55 & 0.58 & - \\
\hline Reaction time ${ }^{a}$ & $0.63(0.12)$ & $0.63(0.12)$ & $0.65(0.13)$ & 2.00 & 0.14 & - \\
\hline Total symptom score ${ }^{a}$ & $6.77(9.99)$ & $9.31(14.85)$ & $13.10(16.80)$ & 15.40 & $<0.001$ & 0.01 \\
\hline Number of symptoms increased ${ }^{b}$ & $2.68(3.59)$ & $3.61(4.73)$ & $5.70(5.84)$ & 16.40 & $<0.001$ & 0.01 \\
\hline
\end{tabular}

Italics indicates significant $p$ value based on Bonferroni-corrected alpha levels $=0.008$

a Each comparison of outcome was controlled for age and respective baseline score in ANCOVA modeling; number of symptoms increased was from baseline report and therefore baseline number of symptoms was not included as a covariate

${ }^{b}$ Increase in number and severity of symptoms based on a previously validated cutoff score (2+ symptoms, increased $1+$ point) to classify athletes as meaningfully changed from baseline [45]

${ }^{c}$ Partial $\eta^{2}$ interpretation for effect size; small $=0.01$, medium $=0.06$, large $=0.14$

with statistically significant differences across all three groups, $F(2,2591)=16.40, p<0.001$, and $\eta_{\mathrm{p}}^{2}=0.01$. The mean increase of individual symptoms above baseline rose in a linear fashion, from early (2.68), mid (3.61), and late season (5.70). Significant differences were again observed at all three levels, with mid-season athletes reporting a greater increase in symptoms from baseline than early-season athletes (mean difference $=$ $0.95, p<0.001)$ and late-season athletes reporting a greater increase in symptoms from baseline than midseason athletes following SRC (mean difference $=1.85$, $p<0.001$ ). Late-season athletes reported significantly more symptoms above baseline than early-season athletes as well (mean difference $=2.80, p<0.001$ ). Similar to TSS, athletes who sustained a SRC during late season reported nearly twice the number of increased symptoms from baseline as athletes in the early-season period (5.70 vs. 2.68). Of the 22 individual symptoms, 9 emerged as statistically different across all three groups (Table 4; Fig. 2). Tukey HSD revealed variation in differences between early-to-mid and mid-to-late, with late-season athletes demonstrating significantly greater symptoms than early athletes for all 9 symptoms.
Similarly, significant differences in being classified as injured from baseline based on increases in individual symptoms $(2+, 1+$ cutoff $)$ were observed between early$(45.45 \%)$, mid- $(50.05 \%)$, and late-season $(63.27 \%)$ injured athletes, $\chi^{2}=10.32, p=0.006, \Phi=0.10$.

\section{Discussion}

The purpose of the current study was to assess the effect of seasonality on acute SRC presentation in a large cohort of American high school football student-athletes within 1-week post-injury. Acute symptom burden, measured by TSS and individual symptom increases, significantly increased as the high school football season advanced. Progressively higher measures of symptom burden were observed across season periods, with athletes in the lateseason period reporting twice the post-injury TSS compared to athletes in the early-season period. Similarly, compared to the early-season group, athletes injured in the late-season period reported almost twice as many individual symptom increases from baseline following SRC.

While recovery was not included as an outcome in the current study, initial symptom burden has been identified as one of the strongest and most consistent predictors of

Table 3 Comparison of the number of significant reliable change rates for each outcome measure among athletes who sustained concussion in the early, mid, and late season

\begin{tabular}{|c|c|c|c|c|c|c|}
\hline Post-concussion outcome $n(\%)$ & Early season & Midseason & Late season & $x^{2 c}$ & $p$ value & $\Phi^{d}$ \\
\hline Verbal memory $^{a}$ & $62(14.83)$ & $352(16.94)$ & $26(26.53)$ & 7.72 & 0.02 & - \\
\hline Visual memory ${ }^{a}$ & $42(10.04)$ & $280(13.47)$ & $16(16.32)$ & 4.58 & 0.10 & - \\
\hline Visual motor speed ${ }^{\mathrm{a}}$ & $30(7.18)$ & $224(10.78)$ & $16(16.32)$ & 8.67 & 0.01 & - \\
\hline Reaction time ${ }^{a}$ & $78(18.66)$ & $440(21.17)$ & $28(28.57)$ & 4.79 & 0.09 & - \\
\hline Total symptom score ${ }^{a}$ & $64(15.31)$ & $482(23.20)$ & $36(36.73)$ & 24.40 & $<0.001$ & 0.1 \\
\hline Number of symptoms increased ${ }^{b}$ & $190(45.45)$ & $1040(50.05)$ & $62(63.27)$ & 10.32 & 0.006 & 0.06 \\
\hline
\end{tabular}

Italics indicates significant $p$ value based on Bonferroni-corrected alpha levels $=0.008$

${ }^{\text {a }}$ Percentages of athletes classified as concussed based on Reliable change indices at the $80 \%$ confidence interval level [44]

${ }^{b}$ Increase in number and severity of symptoms based on a previously validated cutoff score ( $2+$ symptoms, increased $1+$ point) to classify athletes as meaningfully changed from baseline [45]

${ }^{c} X^{2}$ analyses comparing the proportion of athletes classified as concussed based on Reliable change indices at the $80 \%$ confidence interval level [44]

${ }^{\mathrm{d}}$ Phi effect size interpretation values: $[\mathrm{df}=2]$ small $=0.07$, medium $=0.21$; large $=0.35$ 
Table 4 Comparison of individual symptoms for athletes who sustained concussion in the early, mid, and late season

\begin{tabular}{|c|c|c|c|c|c|c|c|c|}
\hline & Descriptive & & & & & Comparison & een season t & \\
\hline & Early & Mid & Late & $F$ & $\overline{p \text { value }}{ }^{a}$ & Early to mid & Mid to late & Early to late \\
\hline Headache & $182(43.54)$ & $898(43.21)$ & $58(59.18)$ & 4.87 & 0.01 & - & - & - \\
\hline Nausea & $12(2.87)$ & $48(2.31)$ & $2(2.04)$ & 0.26 & 0.77 & - & - & - \\
\hline Vomiting & $40(9.57)$ & $332(16.00)$ & $16(16.33)$ & 5.71 & 0.003 & - & - & - \\
\hline Balance & $62(14.83)$ & $426(20.50)$ & 38 (38.78) & 14.38 & $<0.001$ & 0.02 & $<0.001$ & $<0.001$ \\
\hline Dizziness & $86(20.57)$ & 490 (23.58) & $40(40.82)$ & 9.12 & $<0.001$ & 0.38 & $<0.001$ & $<0.001$ \\
\hline Fatigue & $40(9.57)$ & 276 (13.28) & $14(14.29)$ & 2.27 & 0.10 & - & - & - \\
\hline Falling asleep & $58(13.88)$ & $400(19.25)$ & $32(32.65)$ & 9.63 & $<0.001$ & 0.03 & 0.003 & $<0.001$ \\
\hline Sleeping more & $34(8.14)$ & $190(9.14)$ & $18(18.37)$ & 5.14 & 0.06 & - & - & - \\
\hline Sleeping less & $30(7.17)$ & $190(9.14)$ & $14(14.29)$ & 2.54 & 0.08 & - & - & - \\
\hline Drowsiness & $86(20.57)$ & $566(27.23)$ & $36(36.73)$ & 6.72 & 0.001 & 0.13 & 0.09 & 0.003 \\
\hline Light sensitivity & $76(18.18)$ & 484 (23.29) & $30(30.61)$ & 4.39 & 0.01 & - & - & - \\
\hline Noise sensitivity & $70(16.75)$ & $480(23.10)$ & $32(32.65)$ & 7.12 & 0.001 & 0.01 & 0.07 & 0.002 \\
\hline Irritability & $46(11.00)$ & $264(12.70)$ & $16(16.33)$ & 1.11 & 0.33 & - & - & - \\
\hline Sadness & $30(7.18)$ & $178(8.57)$ & $14(14.29)$ & 2.57 & 0.08 & - & - & - \\
\hline Nervousness & $8(1.91)$ & $104(5.00)$ & $8(8.16)$ & 5.23 & 0.01 & - & - & - \\
\hline More emotional & $18(4.31)$ & $150(7.21)$ & $10(10.20)$ & 3.20 & 0.04 & - & - & - \\
\hline Numbness & $22(5.26)$ & $82(3.95)$ & $6(6.12)$ & 1.19 & 0.31 & - & - & - \\
\hline Slowed down & $52(12.44)$ & $448(21.56)$ & 38 (38.78) & 19.14 & $<0.001$ & $<0.001$ & $<0.001$ & $<0.001$ \\
\hline Mentally foggy & $40(9.57)$ & $384(18.48)$ & $36(36.73)$ & 22.43 & $<0.001$ & $<0.001$ & $<0.001$ & $<0.001$ \\
\hline Concentration & $66(15.79)$ & $572(27.53)$ & $36(36.73)$ & 15.69 & $<0.001$ & $<0.001$ & 0.10 & $<0.001$ \\
\hline Memory problems & $28(6.70)$ & $360(17.32)$ & $24(24.49)$ & 17.75 & $<0.001$ & $<0.001$ & 0.14 & $<0.001$ \\
\hline Vision problems & $38(9.09)$ & $246(11.84)$ & $20(20.40)$ & 5.00 & 0.01 & - & - & - \\
\hline
\end{tabular}

Indicates significant $p$ value based on Bonferroni-corrected alpha levels $=0.002$

b Indicates significant $p$ value based on Tukey HSD alpha levels $=0.05$

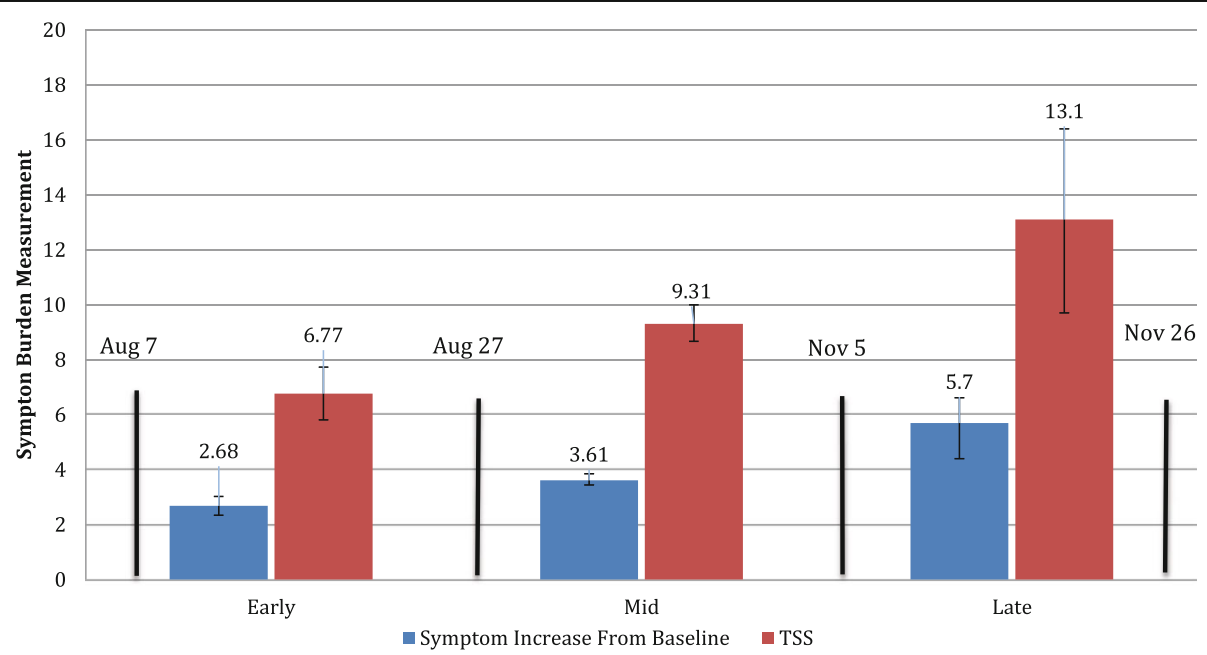

Fig. 1 Symptom burden at early-, mid-, and late-season intervals. Early season interval = August 7-August 26; mid-season = August 27-November 4; late season = November 5 -November 26. Blue bars indicate increase in number of individual symptoms from baseline. Red bars indicate ImPACT total symptom score (TSS). Error bars reflect $95 \% \mathrm{Cl}$ of the mean 


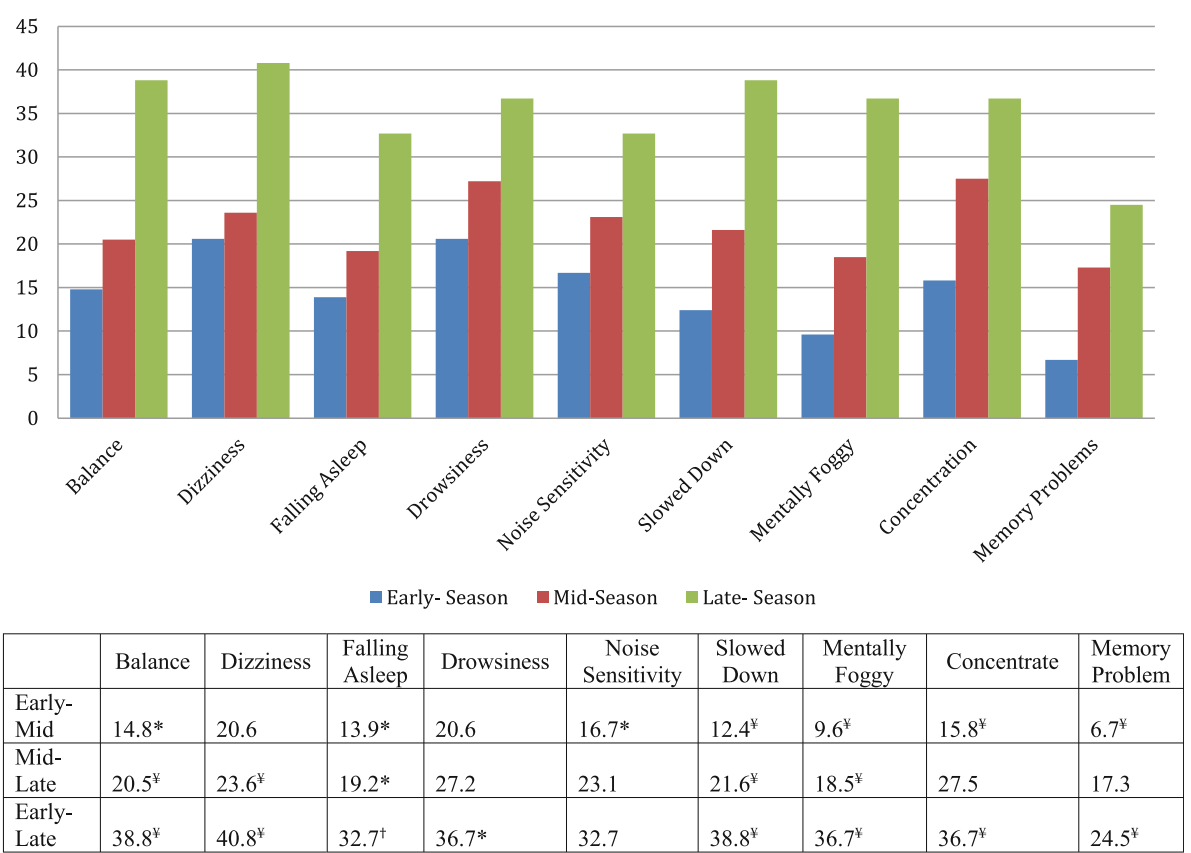

Fig. 2 Percentage of athletes reporting symptoms that statistically differed across early-, mid-, and late-season injuries. Asterisk indicates significant at the $<0.05$ level. Dagger indicates significant at the 0.01 level. Yen sign indicates significant at the $<0.001$ level

prolonged recovery $[24,30,48-52]$. Therefore, more conservative management of athletes who sustain a SRC later in the season may be warranted. Silverberg et al. [53] showed that athletes with higher symptom burden immediately following injury were at increased risk for "symptom spikes" during return to regular activities (RTRA), such as school. Therefore, the timing of injury during the season may influence return-to-school decisions. Clinicians can counsel parents and athletes on the prospect of extended duration for return-to-school and/or return-to-play as a result of late-season injuries, which could reduce concern over lingering symptoms or "symptom spikes" during RTRA.

The effect of season period on acute symptom burden should also be considered in the context of other modifying factors, such as age. Sport participation at the youth and adolescent level places children at higher risk for SRC $[20,54]$ and prolonged recovery $[22,55]$. Should future studies validate the current results, there exist additional implications for those at increased risk of concussion and prolonged recovery, especially youth and adolescent athletes $[33,55]$. While the reporting of acute fatigue did not significantly differ across the three groups, the effect of accumulated fatigue may be a factor worthy of consideration for elite adolescent and high school athletes who play their sport year-round. This is especially true when considering a recent meta-analysis demonstrating that higher athletic training loads over time were associated with increased rates of both injury and fatigue [56]. Alongside heightened awareness by healthcare providers regarding how time of injury may be associated with concussion symptomatology, consideration should be given to the number of pre-season games and practice schedules as well.

The reason for increased symptom burden later in the season is not entirely clear and could be due to a myriad of reasons. An explanation of the current findings may be due to athletes' willingness to report an injury that may preclude a rapid return to play. Athletes may be less likely to report injuries later in the season due to increased desire to play in higher stakes games, which could result in only the more severe injuries being reported. This possibility is further supported given that motivation to not be withheld from competition has been significantly associated with underreporting of concussion [57]. Cumulative head impact burden from the season might also cause a higher manifestation of concussion symptoms, which may lead to increased symptom burden at season's end [58]. These increased symptoms could also be influenced by other factors coinciding with season progression, such as increased academic demands and stress later in the school year, as compared to the pre-season. Other hypothetical explanations for the current findings are increased intensity of playoff games, higher level of competition with faster and stronger athletes, and suboptimal, colder weather conditions in some areas.

The current study is not without limitation. Our sample of high school football athletes who underwent neurocognitive testing may not be generalizable to athletes from other football settings, sports, or sporting levels. Due to the de-identified process of case selection, it 
cannot be guaranteed that a post-injury assessment was an athlete's first concussion in a season. Given that a history of multiple concussions has been associated with increased symptom reporting post-injury, not being able to ensure that a post-injury assessment was an athlete's first SRC in the season presents as a potential confound [59]. The fact that SRC history did not significantly differ across the three groups suggested that sample selection likely buffered the effect of this possible confound. This is also true of the random selection of data and robust sample size of the study [60]. Further, while cut points for season periods were modeled after two previous studies examining effects of season period, due to state differences, potential for injury time misclassification exists. Regardless, a linear trend and variations around the season period thresholds would not have an effect on the progressive increases in post-injury symptom reporting. Lastly, our findings would also be advanced further if the exact mechanism of increased symptom reporting through the season was identified. This could be accomplished by incorporating measures of fatigue or cumulative head impacts in the examination of symptom reporting trends in different season periods.

\section{Conclusions}

Symptom burden following SRC progressively increases through the advancement of the season in high school American football. While further validation is required, these findings suggest that SRC sustained later in-season may require more conservative management with regard to return-to-learn and play activities. Further study is needed to determine the etiology of greater symptom burden reported later in the season.

\section{Acknowledgements}

Not applicable.

\section{Funding}

No grants or outside funding supported this work.

\section{Availability of data and materials \\ Supporting data is available upon request (see the corresponding author email).}

\section{Authors' contributions}

BLB, AWK, AMYK, ZYK, CMB, GSS, and SLZ contributed to the conception, design, research, and writing of this manuscript. All authors read and approved the final manuscript.

\section{Ethics approval and consent to participate}

Institutional Review Board (IRB) approval was obtained prior to analysis (IRB\# 120991). Written informed consent was obtained from the student-athlete and/or a parent/guardian.

\section{Consent for publication}

Not applicable.

\section{Competing interests}

GS Solomon is a consultant for the Nashville Predators, Tennessee Titans, and the athletic departments of Tennessee Tech University and the University of Tennessee, fees paid to institution. He is also a consultant to the National Football League Department of Health and Safety. CM Bonfield serves as an unaffiliated neurotrauma consultant for the NFL. BL Brett, ZY Kerr, AW Kuhn, SL Zuckerman, and AM Yengo-Kahn declared no conflicts of interest.

\section{Publisher's Note}

Springer Nature remains neutral with regard to jurisdictional claims in published maps and institutional affiliations.

\section{Author details}

'Department of Psychology, Veterans Affairs Connecticut Healthcare System, West Haven, CT, USA. ${ }^{2}$ Department Counseling, Educational Psychology and Research, University of Memphis, Memphis, TN, USA. ${ }^{3}$ Vanderbilt Sports Concussion Center, Vanderbilt University School of Medicine, Nashville, TN, USA. ${ }^{4}$ Department of Neurological Surgery, Vanderbilt University Medical Center, Nashville, TN, USA. ${ }^{5}$ Department of Exercise and Sport Science, University of North Carolina, Chapel Hill, NC, USA.

Received: 8 November 2017 Accepted: 22 January 2018

Published online: 31 January 2018

\section{References}

1. Barlow KM, Crawford S, Stevenson A, Sandhu SS, Belanger F, Dewey D. Epidemiology of postconcussion syndrome in pediatric mild traumatic brain injury. Pediatrics. 2010;126(2):e374-81.

2. Kirkwood MW, Yeates KO, Wilson PE. Pediatric sport-related concussion: a review of the clinical management of an oft-neglected population. Pediatrics. 2006;117(4):1359-71.

3. Bryan MA, Rowhani-Rahbar A, Comstock RD, Rivara F, Collaborative SSCR. Sports- and recreation-related concussions in US youth. Pediatrics. 2016; 138(1). https://doi.org/10.1542/peds.2015-4635.

4. Lovell MR, Fazio V. Concussion management in the child and adolescent athlete. Curr Sports Med Rep. 2008;7(1):12-5.

5. Nationala: Report on trends and participation in organized youth sports. 2008.

6. Nationalb: 2014-15 high school athletics participation survey. 2016.

7. Gessel L, Fields S, Collins C, Dick R, Comstock R. Concussions among United States high school and collegiate athletes. J Athl Train. 2007:42(4):495-503.

8. Collins C, LB MK, Ferketich AK, Andridge R, Xiang H, Comstock RD. Concussion characteristics in high school football by helmet age/ recondition status, manufacturer, and model. Am J Sports Med. 2016;44(6): 1382-90.

9. O'Connor KL, Baker MM, Dalton SL, Dompier TP, Broglio SP, Kerr ZY. Epidemiology of sport-related concussions in high school athletes: National Athletic Treatment, Injury and Outcomes Network (NATION), 2011-2012 through 2013-2014. J Athl Train. 2017;52(3):175-85

10. Baugh CM, Kroshus E, Bourlas AP, Perry Kl. Requiring athletes to acknowledge receipt of concussion-related information and responsibility to report symptoms: a study of the prevalence, variation, and possible improvements. J Law Med Ethics. 2014;42(3):297-313.

11. Gibson TB, Herring SA, Kutcher JS, Broglio SP. Analyzing the effect of state legislation on health care utilization for children with concussion. JAMA Pediatr. 2015;169(2):163-8.

12. AA LR, Nelson LD, Connelly PK, Walter KD, MA MC. Sport-related concussion reporting and state legislative effects. Clin J Sport Med. 2016;26(1):33-9.

13. Institute $\mathrm{o}$, Medicine: Sports-related concussions in youth: improving the science, changing the culture. 2015; https:/www.nap.edu/resource/18377/concussionsRB.pdf. Accessed September, 2015, 2015.

14. National C, Athletic, Association. 2014-15 sports medicine handbook 2015; http://www.ncaapublications.com/DownloadPublication. aspx?download=MD15.pdf. Accessed March 16, 2015.

15. Covassin T, Elbin RJ, Harris W, Parker T, Kontos A. The role of age and sex in symptoms, neurocognitive performance, and postural stability in athletes after concussion. Am J Sports Med. 2012;40(6):1303-12.

16. Covassin T, Moran R, Elbin RJ. Sex differences in reported concussion injury rates and time loss from participation: an update of the National Collegiate Athletic Association Injury Surveillance Program from 2004-2005 through 2008-2009. J Athl Train. 2016:51(3):189-94.

17. Nelson LD, Guskiewicz KM, Marshall SW, et al. Multiple self-reported concussions are more prevalent in athletes with ADHD and learning disability. Clin J Sport Med. 2016a;26(2):120-7. 
18. Morgan CD, Zuckerman SL, Lee YM, et al. Predictors of postconcussion syndrome after sports-related concussion in young athletes: a matched case-control study. J Neurosurg Pediatr. 2015;15(6):589-98.

19. Babcock L, Byczkowski T, Wade SL, Ho M, Mookerjee S, Bazarian JJ. Predicting postconcussion syndrome after mild traumatic brain injury in children and adolescents who present to the emergency department. JAMA Pediatr. 2013;167(2):156-61.

20. Guskiewicz K, Weaver N, Padua D, Garrett WJ. Epidemiology of concussion in collegiate and high school football players. Am J Sports Med. 2000;28(5):643-50.

21. Knox CL, Comstock RD, McGeehan J, Smith GA. Differences in the risk associated with head injury for pediatric ice skaters, roller skaters, and in-line skaters. Pediatrics. 2006;118(2):549-54.

22. Kerr ZY, Zuckerman SL, Wasserman EB, Covassin T, Djoko A, Dompier TP. Concussion symptoms and return to play time in youth, high school, and college American football athletes. JAMA Pediatr. 2016a; 170(7):647-53.

23. Mihalik JP, Register-Mihalik J, Kerr ZY, Marshall SW, McCrea MC, Guskiewicz KM. Recovery of posttraumatic migraine characteristics in patients after mild traumatic brain injury. Am J Sports Med. 2013; 41(7):1490-6

24. Iverson GL, Gardner AJ, Terry DP, et al. Predictors of clinical recovery from concussion: a systematic review. Br J Sports Med. 2017:51(12): 941-8.

25. Sandel N, Schatz P, Goldberg K, Lazar M. Sex-based differences in cognitive deficits and symptom reporting among acutely concussed adolescent lacrosse and soccer players. Am J Sports Med. 2016;45(4): 937-44.

26. Covassin T, Stearne D, Elbin R. Concussion history and postconcussion neurocognitive performance and symptoms in collegiate athletes. J Athl Train. 2008;43(2):119-24

27. Iverson GL, Gaetz M, Lovell MR, Collins MW. Cumulative effects of concussion in amateur athletes. Brain Inj. 2004;18(5):433-43.

28. Gardner RM, Yengo-Kahn A, Bonfield CM, Solomon GS. Comparison of baseline and post-concussion ImPACT test scores in young athletes with stimulant-treated and untreated ADHD. Phys Sportsmed. 2017;45(1):1-10.

29. Field M, Collins MW, Lovell MR, Maroon J. Does age play a role in recovery from sports-related concussion? A comparison of high school and collegiate athletes. J Pediatr. 2003;142(5):546-53.

30. Brown DA, Elsass JA, Miller AJ, Reed LE, Reneker JC. Differences in symptom reporting between males and females at baseline and after a sports-related concussion: a systematic review and meta-analysis. Sports Med. 2015;45(7): 1027-40.

31. Covassin T, Schatz P, Swanik CB. Sex differences in neuropsychological function and post-concussion symptoms of concussed collegiate athletes. Neurosurgery. 2007;61(2):345-50. discussion 350-341

32. Ellis MJ, Ritchie $L J$, Koltek M, et al. Psychiatric outcomes after pediatric sports-related concussion. J Neurosurg Pediatr. 2015;16(6):709-18.

33. Kerr ZY, Register-Mihalik JK, Kroshus E, Baugh CM, Marshall SW. Motivations associated with nondisclosure of self-reported concussions in former collegiate athletes. Am J Sports Med. 2016b;44(1):220-5.

34. Kuhn A, Zuckerman S, Yengo-Kahn A, et al. Factors associated with playing through a concussion. Clin Neurosurg. 2017;64(Suppl 1):211-216. https://doi. org/10.1093/neuros/nyx294.

35. Dompier TP, Kerr ZY, Marshall SW, et al. Incidence of concussion during practice and games in youth, high school, and collegiate American football players. JAMA Pediatr. 2015;169(7):659-65.

36. Zuckerman SL, Totten D, Rubel K, et al. Mechanisms of injury as a diagnostic predictor of sport-related concussion severity in football, basketball, and soccer: results from a regional concussion registry. Neurosurgery. 2016c; 63(Suppl 1):169.

37. Immediate post-concussion assessment testing (ImPACT) test: Technical manual. . 2012; https://www.impacttest.com/pdf/ImPACTTechnicalManual. pdf. Accessed April 6, 2013.

38. Kuhn AW, Solomon GS. Supervision and computerized neurocognitive baseline test performance in high school athletes: an initial investigation. J Athl Train. 2014;49(6):800-5.

39. Daneshvar DH, Nowinski CJ, McKee AC, Cantu RC. The epidemiology of sport-related concussion. Clin Sports Med. 2011;30(1):1-17.
40. McCrory P, Meeuwisse W, Johnston K, et al. Consensus statement on concussion in sport: the 3rd International Conference on Concussion in Sport held in Zurich, November 2008. Br J Sports Med. 2009;43(Suppl 1):i76-90.

41. McCrory P, Meeuwisse WH, Aubry M, et al. Consensus statement on concussion in sport: the 4th International Conference on Concussion in Sport held in Zurich, November 2012. Br J Sports Med. 2013;47(5):250-8.

42. Steiner ME, Berkstresser BD, Richardson L, Elia G, Wang F. Full-contact practice and injuries in college football. Sports Health. 2016;8(3):217-23.

43. Hootman JM, Dick R, Agel J. Epidemiology of collegiate injuries for 15 sports: summary and recommendations for injury prevention initiatives. J Athl Train. 2007:42(2):311-9.

44. Iverson GL, Lovell MR, Collins MW. Interpreting change on ImPACT following sport concussion. Clin Neuropsychol. 2003;17(4):460-7.

45. Hearps SJ, Takagi M, Babl FE, et al. Validation of a score to determine time to postconcussive recovery. Pediatrics. 2017:139(2)

46. Feddermann-Demont N, Echemendia RJ, Schneider KJ., et al. What domains of clinical function should be assessed after sport-related concussion? A systematic review. Br J of Sport Med. 2017;51(11):903-18.

47. Dunn O. Multiple comparisons among means. J Am Stat Assoc. 1961; 56(293):52-64

48. Heyer GL, Schaffer CE, Rose SC, Young JA, McNally KA, Fischer AN. Specific factors influence postconcussion symptom duration among youth referred to a sports concussion clinic. J Pediatr. 2016;174:33-8:e32.

49. Iverson $\mathrm{G}$. Predicting slow recovery from sport-related concussion: the new simple-complex distinction. Clin J Sport Med. 2007;17(1):31-7.

50. McCrory P, Meeuwisse W, Dvorak J, et al. Consensus statement on concussion in sport-the 5(th) international conference on concussion in sport held in Berlin, October 2016. Br J Sports Med. 2017;51(11):838-47.

51. Zemek R, Barrowman N, Freedman SB, et al. Clinical risk score for persistent Postconcussion symptoms among children with acute concussion in the ED. JAMA. 2016;315(10):1014-25.

52. Zuckerman SL, Yengo-Kahn AM, Buckley TA, Solomon GS, Sills AK, Kerr ZY. Predictors of postconcussion syndrome in collegiate student-athletes. Neurosurg Focus. 2016;40(4):E13.

53. Silverberg ND, Iverson GL, McCrea M, Apps JN, Hammeke TA, Thomas DG Activity-related symptom exacerbations after pediatric concussion. JAMA Pediatr. 2016:170(10):946-53.

54. Abrahams S, Fie SM, Patricios J, Posthumus M, September AV. Risk factors for sports concussion: an evidence-based systematic review. Br J Sports Med. 2014;48(2):91-7.

55. Nelson LD, Guskiewicz KM, Barr WB, et al. Age differences in recovery after sport-related concussion: a comparison of high school and collegiate athletes. J Athl Train. 2016b;51(2):142-52.

56. Jones CM, Griffiths PC, Mellalieu SD. Training load and fatigue marker associations with injury and illness: a systematic review of longitudinal studies. Sports Med. 2017:47(5):943-74.

57. McCrea M, Hammeke T, Olsen G, Leo P, Guskiewicz K. Unreported concussion in high school football players: implications for prevention. Clin J Sport Med. 2004;14(1):13-7.

58. Broglio SP, Eckner JT, Kutcher JS. Field-based measures of head impacts in high school football athletes. Curr Opin Pediatr. 2012;24(6):702-8.

59. Silverberg ND, Lange RT, Millis SR, et al. Post-concussion symptom reporting after multiple mild traumatic brain injuries. J Neurotrauma. 2013;30(16): 1398-404.

60. Coombs W, Algina J, Altman D. Univariate and multivariate omnibus hypothesis tests selected to control type I error rates when population variances are not necessarily equal. Rev Educ Res. 1996;66(2):137-79. 